University for Business and Technology in Kosovo

UBT Knowledge Center

Nov 2nd, 9:00 AM - Nov 3rd, 5:00 PM

\title{
The Calculation of a Concrete Reinforcement Under the Action of Torsion Moment, According to Eurocode and Albanian Technical Rules
}

Julian Kasharaj

Polytechnic University of Tirana

Igli Kondi

Polytechnic University of Tirana

Eda Gjeka

Polytechnic University of Tirana

Follow this and additional works at: https://knowledgecenter.ubt-uni.net/conference

Part of the Architecture Commons

\section{Recommended Citation}

Kasharaj, Julian; Kondi, Igli; and Gjeka, Eda, "The Calculation of a Concrete Reinforcement Under the Action of Torsion Moment, According to Eurocode and Albanian Technical Rules" (2012). UBT International Conference. 12.

https://knowledgecenter.ubt-uni.net/conference/2012/all-events/12

This Event is brought to you for free and open access by the Publication and Journals at UBT Knowledge Center. It has been accepted for inclusion in UBT International Conference by an authorized administrator of UBT Knowledge Center. For more information, please contact knowledge.center@ubt-uni.net. 


\title{
The calculation of a concrete reinforced element under the action of torsion moment, according to Eurocode and Albanian Technical Rules \\ Msc.Ing.Julian Kasharaj ${ }^{1}$, Msc.Ing.Igli Kondi ${ }^{1}$, Eda Gjeka ${ }^{2}$
}

\begin{abstract}
${ }^{1}$ Department of Construction Engineering, Polytechnic University of Tirana
${ }^{2}$ Student at the Faculty of Civil Engineering, Polytechnic University of Tirana

ABSTRACT. The objective of this research is to introduce the reader to the calculation of a concrete reinforced element under the action of the torsion moment by comparing the two methods, Eurocode and Albanian Technical Rules. Particularly we will present the factors that affect the calculation and the final result. During a long period of time the action of torsion on a concrete reinforced element is not considered to be very important. The traditional calculating methods led to designing with reserves. As a result the longitudinal and transversal reinforcement due to bending, shear, compression or tension was enough even for torsion. With the progress of the calculating methods are designs concrete reinforced elements that have smaller dimensions and a reduced reinforcement. Consequently it is important to calculate correctly even the effect of torsion. Usually torsion is combined with bending and shear. In some cases it is combined with compression or tension. When torsion is combined with bending, shear, compression or tension, the concrete reinforced element must be controlled carefully in order to consider all these effects. In fact, torsion is noticed very often in the performance of a concrete reinforced element. Usually the vertical loads don't pass through the center of gravity of the section. Almost every time they are deflected, causing torsion moments besides bending moments and shear forces. But this kind of torsion is not considered. Here we come to a question, when should torsion be considered and when not? This question and many other ones will be answered in this article. The similarities, differences and the factors that affect on both chosen methods will also be part of the article, especially the effect of section dimensions.
\end{abstract}

Keywords: torsion moment, Eurocode, Albanian technical rules, section dimensions.

\section{INTRODUCTION}

TORSION IS DIVIDED INTO "PRIMARY" AND "SECONDARY". THE FIRST ONE IS CAUSED BY LOADS THAT REQUIRE TORSION REACTION OF THE CONCRETE REINFORCED ELEMENT (EG. BEAM) IN ORDER TO BE EQUILIBRATED. THUS, TO ACHIEVE AN EQUILIBRIUM IT IS REQUIRED A TORSION BEARING CAPACITY OF THE CONCRETE REINFORCED ELEMENT (BEAM). AS AN EXAMPLE MAY BE MENTIONED THE BEAM THAT CARRIES A CORBEL SLAB. THE EQUILIBRIUM OF THE CORBEL SLAB IS POSSIBLE ONLY IF THE BEAM IS ABLE TO BEAR THE TORSION MOMENT THAT THE SLAB TRANSMITS TO THE BEAM. IN THIS CASE, IT MUST BE CALCULATED THE BEARING CAPACITY OF THE ELEMENT ACCORDING TO THE FIRST BOUNDARY CONDITION BUT ALSO ACCO RDING TO THE SECOND BOUNDARY CONDITION. 


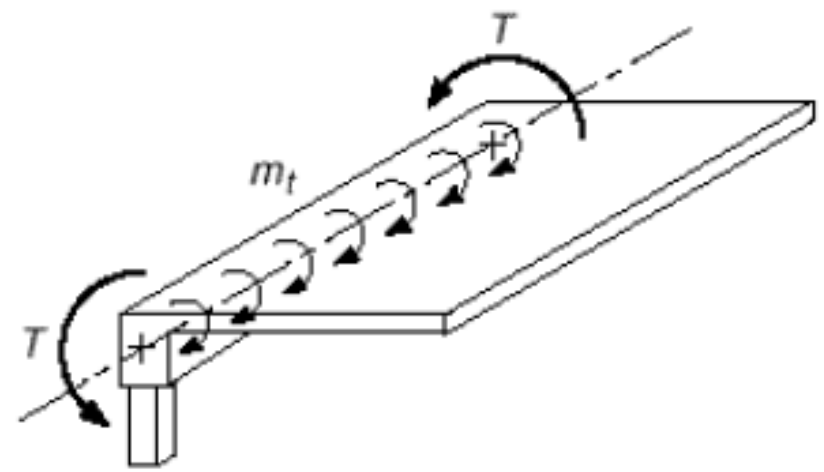

Fig.1

The secondary torsion is not related to the equilibrium. E.g. a terminal beam of a concrete reinforced structure absorbs the bending moments of the slab that is fixed on the beam. So the bending moments of the slab on her supporting area on the beam, are transformed into bending moments for the beam. If we cancel the torsion bearing capacity of the beam, the torsion moment disappears. Anyway the equilibrium of the slab is not affected. Generally in this case torsion is ignored. So it is not calculated the bearing capacity according to the finite boundary condition. We consider sufficient the minimal longitudinal and transverse reinforcement in order to prevent cracks caused by torsion. So we perform only the calculation according to the service boundary condition. However, in any case we must be sure that the structure is able to provide the equilibrium and the right bearing capacity, in every single part. For the beams that carry slabs which have a span not greater than $6 \mathrm{~m}$, "secondary" torsion stresses may be ignored.

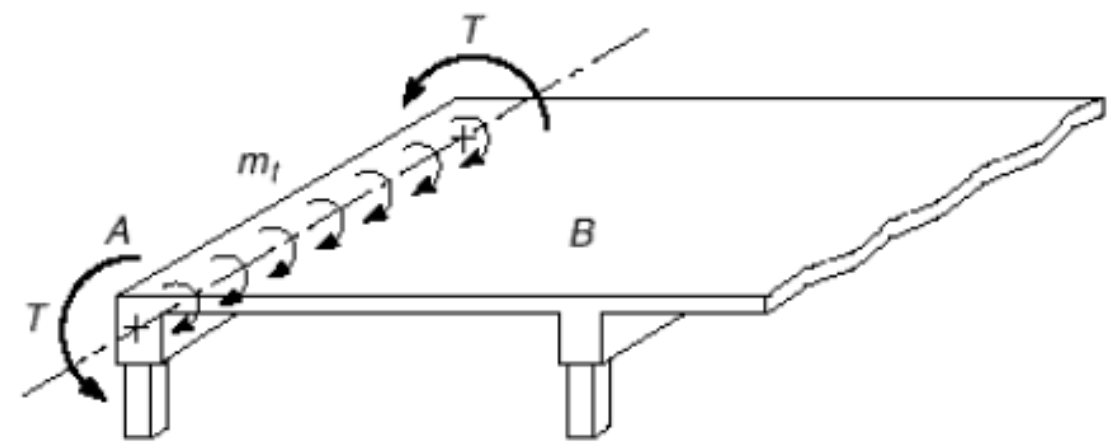

Fig.2

Usually torsion is combined with bending and shear. In some cases it is combined even with compression or tension. When torsion is combined with bending, shear, compression or tension, the concrete reinforced element must be controlled carefully in order to consider all these effects. Certainly for the elastic phase it may be used the principle of the independent action but for the phase that comes after the elastic one, it cannot be used. In fact the problem is very complex. In practice, the effects such as bending, shear, compression, tension are studied separated and are assembled the amounts of reinforcement that they require. Concrete reinforced beams that work in torsion, act differently when they are cracked and when they are not. The greatest difference is about the torsion rigidity. The rigidity of the cracked element is equal to $1 / 5$ of the not cracked element. For the not cracked element, stresses are calculated using the formulas. The cracked element is calculated according to a pipe that has a thin wall, materialized as a space frame truss which is made of compressed concrete elements that are inclined according to the longitudinal axis of the element and tensioned elements represented by the longitudinal and transverse reinforcement. 


\section{THE CALCULATION BASED ON THE ALBANIAN TECHNICAL RULES FOR AN ELEMENT THAT HAS A RECTANGULAR SECTION, UNDER THE ACTION OF THE TORSIONAL MOMENT}

When bending and torsion act on the concrete element ate the same time, they provide a stressed condition which is one of the most difficult problems. According to the Albanian designing code is studied the method of the spatial cracks which is based on the on the boundary phase of the stressed condition. We consider that in this phase, the longitudinal and transverse reinforcement that is interrupted by the space cracks, reaches the boundary rated strength $\mathrm{R}_{\mathrm{sw}, \mathrm{n}}$ ( during the phase of the calculating boundary condition it reaches $\mathrm{R}_{\mathrm{s}}$ ), concrete in the compressed area reaches $\mathrm{Rbn}$ ( during the phase of the rated condition it reaches $\mathrm{R}_{\mathrm{b}}$ ).

$R_{S}$ - Steel strength

$R_{b n}$ - rated concrete strength

$R_{b}$ - Concrete strength

The collapse scheme showed in Fig.3a is valid for the case of the double action of bending and torsion at the same time, but shear force is considered zero or very low.

The collapse scheme showed in Fig.3b is in the case of double action of the torsion moment and shear force at the same time but the bending moment is considered with a very small value.

The collapse according to Fig. $3 \mathrm{c}$ is in the case of the action of the torsion moment (the bending moment is very low), in the bending compressed area the compressed reinforcement is very small compared to the one in front of it.

According to KTP (Albanian Technical Rules) the calculation must be done for all three calculating schemes shown in the Fig. 3 and we should consider only the calculation that provides the smallest bearing capacity. Basing on the three schemes it is tested the bearing capacity of the spatial transversal cut, taking into account the condition: the torsion moment, that operates on the axis that passes through the gravity point of the compressed area, is smaller than the sum of the moments caused by the interior calculating forces, that are carried by the transversal and longitudinal reinforcement, interrupted by the spatial transversal cut, towards the same axis.

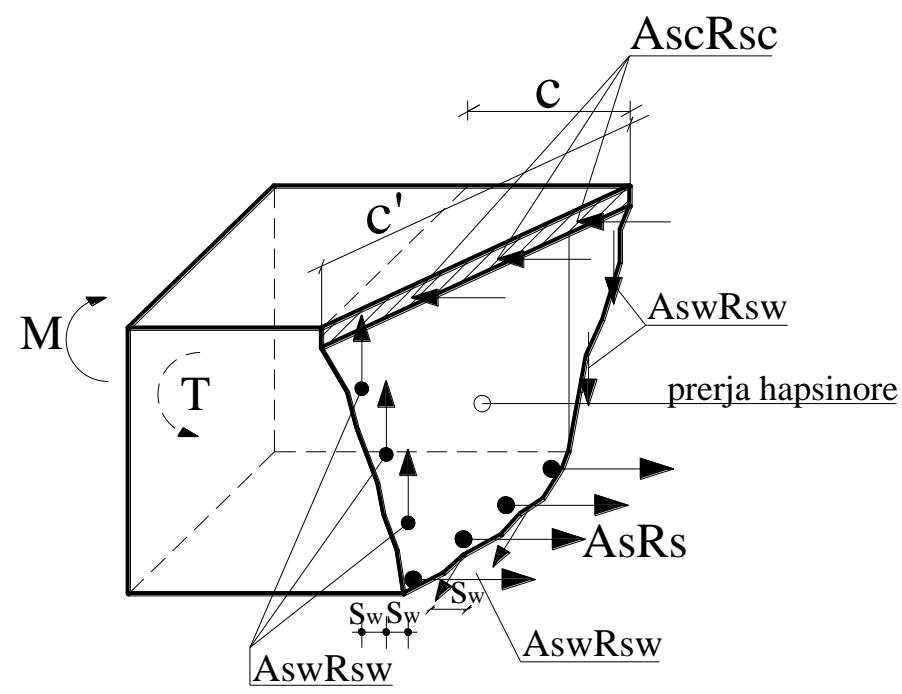

Fig. 3 
Asc

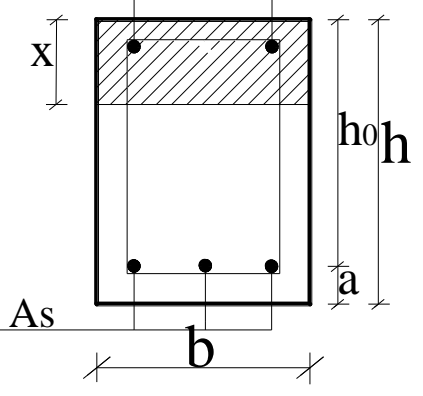

Fig.3a

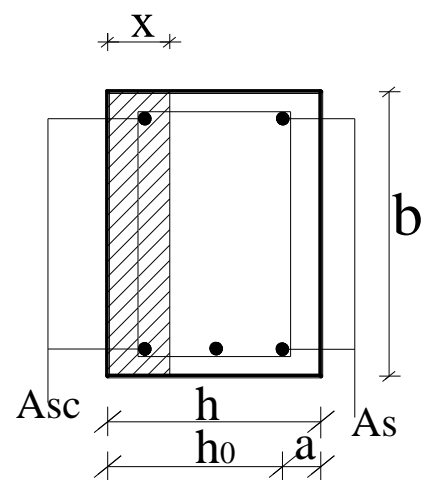

Fig.3b

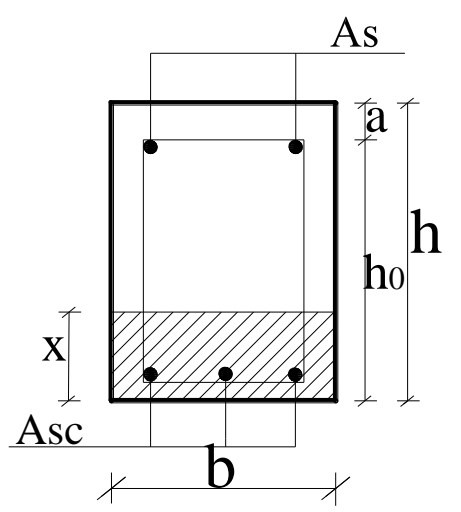

Fig.3c

$T \leq \frac{R_{s} A_{s}\left(h_{0}-0.5 x\right)\left(1+\varphi_{w} \delta \lambda^{2}\right)}{\left(\varphi_{q} \lambda+\chi\right)}$

$\lambda=\frac{c}{b} ; \quad \delta=\frac{b}{2 h+b}$

$\varphi_{w}=\frac{b}{s_{w}} \frac{R_{s w} A_{s w}}{R_{s} A_{s}}$

$\chi=\frac{M}{T} ; \quad \varphi_{q}=1+0.5 h \frac{Q}{T}$

$\mathrm{M} \rightarrow$ bending moemnt

$\mathrm{T} \rightarrow$ torsional moment

$\mathrm{Q} \rightarrow$ shear force

As $\rightarrow$ the surface of the tensioned reinforcement area for each studied scheme Asc $\rightarrow$ the surface of the compressed reinforcement area for each studied scheme $\mathrm{b}, \mathrm{h} \rightarrow$ the dimensions of the section for each studied scheme 
$c \rightarrow$ the length of the cpmressed area, projected on the longitudinal axis of the elemnt

$\mathrm{x} \rightarrow$ the height of the compressed area, calculated by the formula:

$A_{s} R_{s}-A_{s c} R_{s c}-b x R_{b}=0$

For $\mathrm{M}=0$ and $\mathrm{Q}=0$ (pure torsion) we have: $\chi=0$ and $\varphi_{q}=0$

According the schemes on Fig.2 we have:

For Fig.2a:

$\chi=\frac{M}{T} \quad \varphi_{q}=1.0$

For Fig.2b:

$$
\chi=\frac{M}{T} \quad \varphi_{q}=1+0.5 h \frac{Q}{T}
$$

For Fig.2.c:

$\chi=-\frac{M}{T} \quad \varphi_{q}=1.0$

We should emphasize that the most dangerous transverse cut that has the lowest bearing capacity is the one that has the smallest projection c. It may be defined through tests; we define different values for "c" in the calculating formula, until we find the right one. Values must be in the range:

$0 \leq c \leq 2 h+b$

According to the tests, it must be verified the condition:

$\varphi_{w, \min } \leq \varphi_{w} \leq \varphi_{w, \max }$

$\varphi_{w, \min }=0.5\left(1-\frac{M}{M_{u}}\right)$

$\varphi_{w, \max }=1.5\left(1-\frac{M}{M_{u}}\right)$

$\mathrm{M} \rightarrow$ calculating bending moment

$\mathrm{Mu} \rightarrow$ the boundary moment that can carry the transverse cut

If we have $\varphi_{w} \leq \varphi_{w, \min }$ in (1) and (2) AsRs multiplies $\frac{\varphi_{w}}{\varphi_{w, \min }}$

If : $\mathrm{T} \leq 0.5 \mathrm{Qh}$ the calculation $\mathrm{i}$ done according to the second scheme, basing on the condition:

$Q \leq Q_{w}+Q_{b}-3 \frac{T}{b}$

$Q_{w} \rightarrow$ The part of shearforce that is carried by stirrups

$Q_{b} \rightarrow$ The part of shear force that is carried by concrete.

The bearing capacity of the compressed concrete in the inclined cut, during the action of torsional moment "T" and bending moment " $\mathrm{M}$ ", is insured only if is fulfilled the condition:

$$
T \leq 0.1 b b^{2} h R_{b}, \quad \mathrm{~h} \geq \mathrm{b}
$$

For concrete classes greater than $\mathrm{B} 30, \mathrm{Rb}$ is equal to $\mathrm{Rb}$ for $\mathrm{B} 30$. For concrete classes lower than $\mathrm{B} 30, \mathrm{Rb}$ takes tha value for the respective class. 

THE CALCULATION BASED ON EUROCODE FOR AN ELEMENT THAT HAS A RECTANGULAR
SECTION, UNDER THE ACTION OF THE TORSIONAL MOMENT

The calculation of an element that has a rectangular section, under the action of the torsional moment, includes:
a. To define the longitudinal reinforcement, related to torsion
b. To define the transversal reinforcement (stirrups), related to torsion
c. To control compression in concrete

In this case we do know: the dimensions of the section, concrete's class, steel's class, and the torsion moment. A full section is studied as a ring section that has a uniform wall thickness.

$t_{e f}=\frac{A}{u}$

A - The full surface of the transverse section of the concrete element, included inside in the external perimeter

$\mathrm{u}$ - The external perimeter of the transverse section

$t_{e f}-$ The effective wall thickness of the ring

It is recommended that $t_{e f}$ not to exceed the value of twice of the distance of the center of gravity of the reinforcement from the closest side of the section, $t_{e f} \leq 2 \mathrm{~d}$ '.
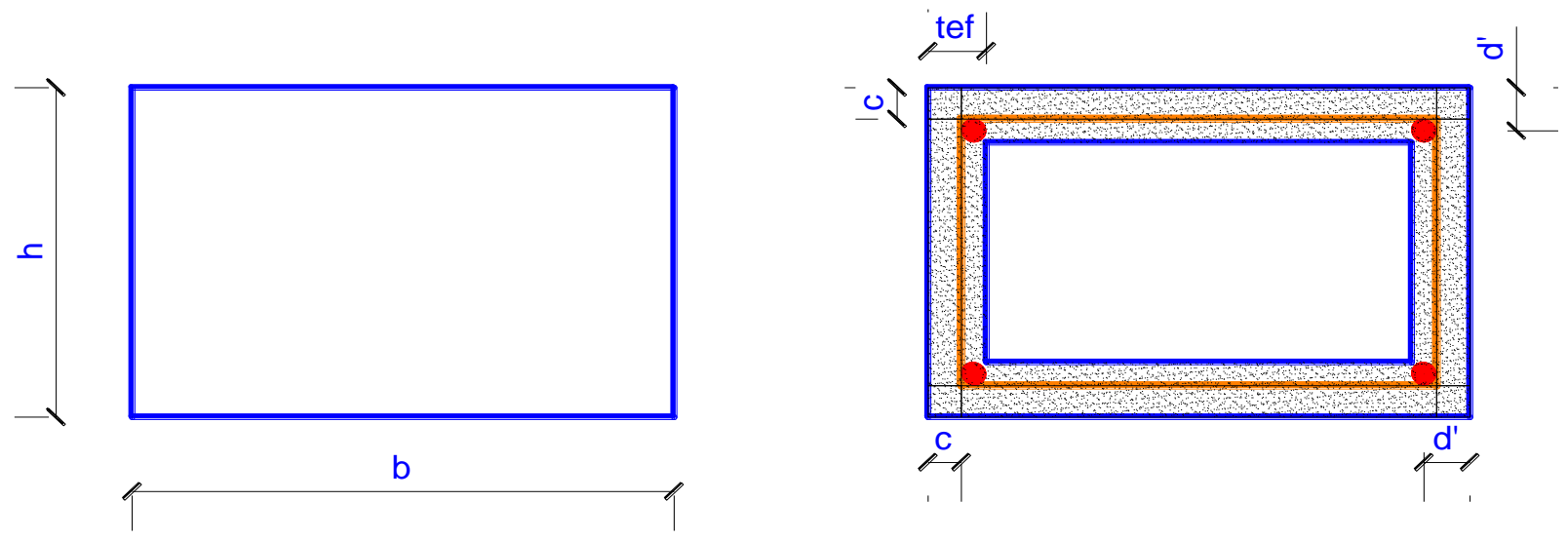

Fig.4

Basing on Fig.4 we have:

$\mathrm{A}=\mathrm{b} \cdot \mathrm{h}$

$\mathrm{u}=2 \cdot(\mathrm{b}+\mathrm{h})$ 


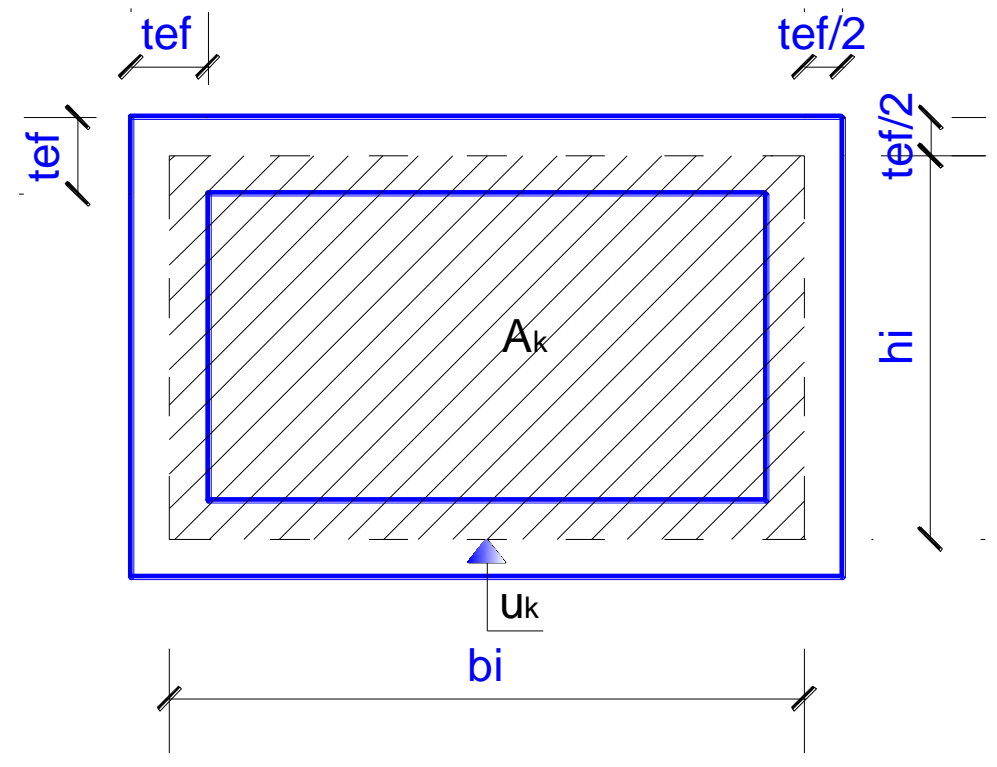

Fig.5

The line that goes through the middle of the ring's wall thickness, on a distance $t_{\mathrm{e}} / 2$ from the external perimeter, includes a surface $A_{k}=b_{i} \cdot h_{i}$. The length of the line that goes through the middle of the ring's wall thickness is $u_{k}=$ $2 \cdot\left(b_{i}+h_{i}\right)$. Closed stirrups may be placed along the thickness $t_{e f}$ of the ring or just along the external perimeter of the section or even along the interior perimeter of the ring. Stirrups are placed perpendicular to the longitudinal axis of the element with a constant spacing $\mathrm{s}$. The longitudinal reinforcement surrounded by stirrups is $\mathrm{A}_{\mathrm{sl}}$. A transverse section of the beam, which is located between two stirrups, interrupts the compressed concrete elements inclined with an angle $\theta$. Every side of the section that has a length $b_{i}$ or $h_{i}$ interrupts some compressed concrete elements. The number of compressed elements interrupted by the secton side that $h$ as a length $h_{i}$ is $h_{i} /(s \cdot \operatorname{tg} \theta)$. Each stirrup corresponds to a compressed element that has a width $(\mathrm{s} \cdot \sin \theta)$ and a thickness $\mathrm{t}$. The maximal compressive force that corresponds to a compressed element is $(s \cdot \sin \theta) \cdot t \cdot f_{c d}$.

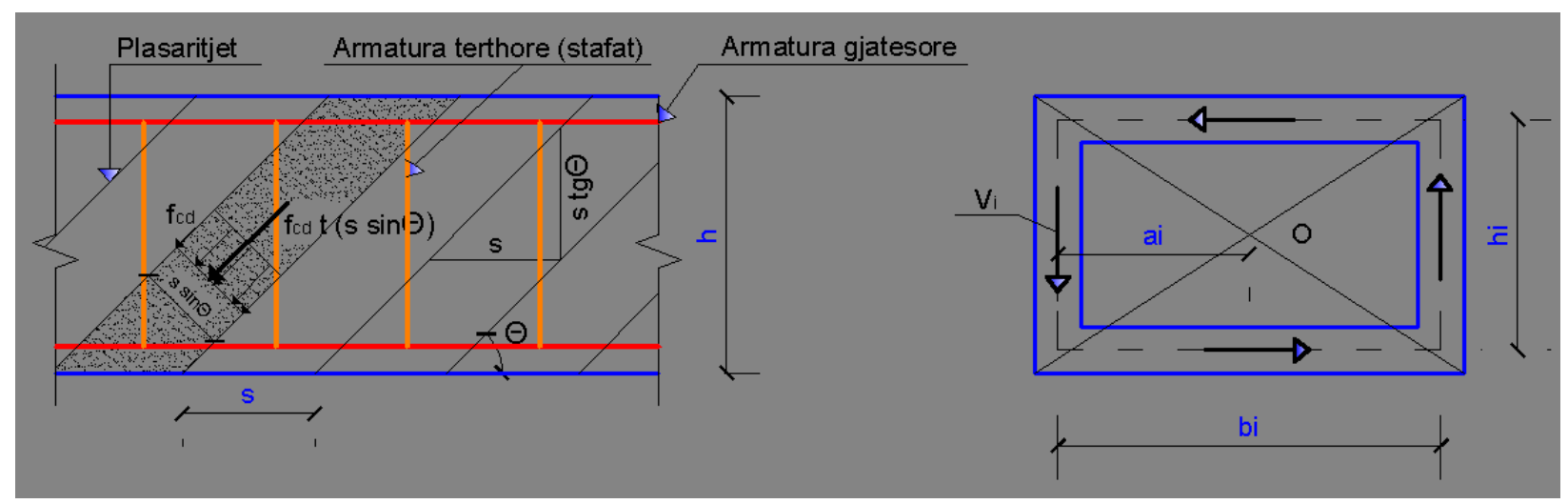

Fig.6

The resultant force of the compressed element projected on plan of the transverse section is:

$V_{i}=\left[(s \cdot \sin \theta) \cdot t \cdot f_{c d}\right]\left[\frac{h_{i}}{s \cdot \operatorname{tg} \theta}\right] \cdot \sin \theta$

The resultant force of the compressed element projected on the longitudinal axis of the element is:

$H_{i}=\left[(s \cdot \sin \theta) \cdot t \cdot f_{c d}\right]\left[\frac{h_{i}}{s \cdot \operatorname{tg} \theta}\right] \cdot \cos \theta$ 
The forces $V_{i}$ and $H_{i}$ belong to the sides of the transverse section that has a length $h_{i}$.

The sum of the moments towards to the pole $\mathrm{O}$ (which is a point picked by chance) is as following:

$T_{E d}=\sum V_{i} \cdot a_{i}$

$T_{E d}=\sum\left[(s \cdot \sin \theta) \cdot t \cdot f_{c d}\right]\left[\frac{h_{i}}{s \cdot \operatorname{tg} \theta}\right] \cdot \sin \theta \cdot a_{i}=f_{c d} \cdot t \cdot \sin \theta \cdot \cos \theta \cdot \operatorname{sh} h_{i} \cdot a_{i}$

$=f_{c d} \cdot t \cdot \sin \theta \cdot \cos \theta \cdot 2 \cdot A_{k}$

The left side of the equation (21) represents the torsional moment $\left(\mathrm{T}_{\mathrm{Ed}}\right)$. The right side of the equation (21) represents the boundary torsional moment that is able to bear the element $\left(T_{R d}\right)$. In order to maintain the beam undestroyed by torsion, the torsional moment must be smaller (or equal in the boundary case) than the boundary bearing moment.

$\mathrm{T}_{\mathrm{Ed}} \leq \mathrm{T}_{\mathrm{Rd}}$

$T_{R d}=f_{c d} \cdot t \cdot \sin \theta \cdot 2 \cdot A_{k}$

In the formula (23) are also included two corrective coefficients $v_{1}$ and $\alpha_{\mathrm{cw}}$. The coefficient $v_{1}$ takes into account the reduction of the bearing capacity of the compressed concrete elements as a result of the possible cracks that are all over the element.

$v_{1}=0.6\left(1-\frac{f_{c k}}{250}\right)$

In the formula (24) the value of $f_{c k}$ is in $\mathrm{MPa}$.

The coefficient $\alpha_{c w}$ considers the interaction between the tensile stresses on the compressed area and the possible stresses that are a result of the normal forces. For the not prestressed concrete reinforced elements $\alpha_{\mathrm{cw}}=1$. Definitely we have:

$T_{R d}=2 \cdot v_{1} \cdot a_{c w} \cdot f_{c d} \cdot A_{k} \cdot t \cdot \sin \theta \cdot \cos \theta$

The boundary bearing torsional moment presented in the formula (25) is related to the bearing capacity of concrete in compression. If the torsional acting moment is greater than the boundary moment, the element is destroyed as a result of the collapse (crumbling) of the concrete. This collapse is not ductile and should be avoided. The sum of the horizontal forces $\mathrm{H}_{\mathrm{i}}$ is as following:

$H=\sum H_{i}=\sum\left[(s \cdot \sin \theta) \cdot t \cdot f_{c d}\right]\left[\frac{h_{i}}{s \cdot \operatorname{tg} \theta}\right] \cdot \cos \theta=\left(f_{c d} \cdot t \cdot \sin \theta \cdot \frac{\cos \theta}{\operatorname{tg} \theta}\right) u_{k}$

This horizontal force will be carried by the longitudinal reinforcement of the element, which is placed along the perimeter of the transverse section.

$\frac{f_{c d} \cdot t \cdot \sin \theta \cdot \cos \theta}{\operatorname{tg} \theta} \cdot u_{k}=A_{s l} \cdot f_{y d}$
$A_{s l}=\frac{f_{c d} \cdot t \cdot u_{k} \cdot \sin \theta \cdot \cos \theta}{\operatorname{tg} \theta \cdot f_{y d}}$

The formula (28) calculates the maximal amount of the longitudinal reinforcement from torsion when the compressive stresses in concrete have reached the value $\mathrm{f}_{\mathrm{cd}}$ or when the torsional acting moment is equal to the value the boundary bearing moment which is calculated by the formula (25). If the stresses in concrete have not reached the value of the strength of concrete in compression $\mathrm{f}_{\mathrm{cd}}$, which is the amount of the longitudinal reinforcement from torsion? In this case the formula (19) would be as following:

$H_{i}=s \cdot \sin \theta \cdot t \cdot \sigma_{c} \cdot\left(\frac{h_{i}}{s \cdot \operatorname{tg} \theta}\right) \cdot \cos \theta$

$\sigma_{\mathrm{c}}-$ the compressive stresses in concrete

In order to calculate $\sigma_{c}$ it is used the expression (21), but in this case we use $\sigma_{c}$ instead of $f_{c d}$

$$
\begin{gathered}
T_{E d}=\sum s \cdot \sin \theta \cdot t \cdot \sigma_{c} \cdot\left(\frac{h_{i}}{s \cdot \operatorname{tg} \theta}\right) \cdot \sin \theta \cdot a_{i}=\sigma_{c} \cdot t \cdot \sin \theta \cdot \cos \theta \cdot \Sigma h_{i} \cdot a_{i} \\
=\sigma_{c} \cdot t \cdot \sin \theta \cdot \cos \theta \cdot 2 \cdot A_{k}
\end{gathered}
$$


$\sigma_{c}=\frac{T_{E d}}{t \cdot \sin \theta \cdot \cos \theta \cdot 2 \cdot A_{k}}$

The horizontal force $\mathrm{H}_{\mathrm{i}}$ is as following:

$H=\Sigma H_{i}=\Sigma\left[(s \cdot \sin \theta) \cdot t \cdot \sigma_{c}\right] \cdot\left[\frac{h_{i}}{(s \cdot \operatorname{tg} \theta)}\right] \cdot \cos \theta=\sigma_{c} \cdot t \cdot \frac{\sin \theta \cdot \cos \theta}{\operatorname{tg} \theta} \cdot u_{k}$

This horizontal force will be carried by the longitudinal reinforcement of the element which is placed all over the perimeter of its transverse section.

$\sigma_{c} \cdot t \cdot \frac{\sin \theta \cdot \cos \theta}{\operatorname{tg} \theta} \cdot u_{k}=A_{s l} \cdot f_{y d}$

$A_{s l}=\sigma_{c} \cdot t \cdot u_{k} \cdot \frac{\sin \theta \cdot \cos \theta}{\operatorname{tg} \theta \cdot f_{y d}}$

In the formula (34) we replace the value of $\sigma_{c}$ with the one calculated by the formula (31)

$A_{s l}=\frac{T_{E d} \cdot t \cdot u_{k} \cdot \sin \theta \cdot \cos \theta}{\operatorname{tg} \theta \cdot f_{y d} \cdot t \cdot \sin \theta \cdot \cos \theta \cdot 2 \cdot A_{k}}$

$A_{s l}=\frac{T_{E d} \cdot u_{k}}{2 \cdot A_{k} \cdot f_{y d} \cdot \operatorname{tg} \theta}$

If the surface of the longitudinal reinforcement $\mathrm{A}_{\mathrm{sl}}$ is known and we want to define the boundary bearing torsional moment that the surface is able to carry, basing on the formula (36) we have:

$T_{R d}=\frac{2 \cdot A_{k} \cdot f_{y d} \cdot \operatorname{tg} \theta \cdot A_{s l}}{u_{k}}$

The vertical component of the compressive force that is represented by a compressed element is $(s \cdot \sin \theta) \cdot t \cdot f_{c d}$. $\sin \theta$. This force is carried by one branch of the stirrup that is placed on the side of the ring that has thicknes $t$ or $t_{e f}$ : $(s \cdot \sin \theta) \cdot t \cdot f_{c d} \cdot \sin \theta=A_{s w} \cdot f_{y w d}$

$A_{s w}=\frac{(s \cdot \sin \theta) \cdot t \cdot f_{c d} \cdot \sin \theta}{f_{y w d}}$

$A_{s w}$ - is the surface of the stirrups placed on the side of the ring that has a thickness $t$ or $t_{e f}$.

$f_{y w d}=f_{y d}-$ is the calculating strength of steel for its action against shear force

The formula (39) defines the maximal amount of the surface of the stirrups when the stresses in concrete are $f_{c d}$.

When stresses in concrete are $\sigma_{c}$ (calculated with the formula (31) we have:

$$
\begin{gathered}
A_{s w}=\frac{s \cdot \sin \theta \cdot t \cdot \sigma_{c} \cdot \sin \theta}{f_{y w d}}=s \cdot \sin \theta \cdot t \cdot \frac{T_{E d}}{t \cdot \sin \theta \cdot \cos \theta \cdot 2 \cdot A_{k}} \cdot \frac{\sin \theta}{f_{y w d}} \\
=\frac{T_{E d} \cdot s}{2 \cdot A_{k} \cdot \operatorname{cotg} \theta \cdot f_{y w d}}
\end{gathered}
$$

$A_{s w}=\frac{T_{E d} \cdot s}{2 \cdot A_{k} \cdot \operatorname{cotg} \theta \cdot f_{y w d}}$

If we have the surface of the reinforcement of the stirrups $\mathrm{A}_{\mathrm{sw}}$ and we want to define the boundary bearing torsion moment that the stirrups carry, from the formula (41) we have:

$T_{R d}=\frac{2 \cdot A_{k} \cdot \operatorname{cotg} \theta \cdot f_{y w d} \cdot A_{s w}}{s}$

So far we have defined three boundary torsional moments using the formulas (25), (37) and (42). The first one is related to the bearing capacity of concrete in compression; the second one is related to the bearing capacity of the longitudinal reinforcement and the third one is related to the bearing capacity of the stirrups. The steps that we should follow to calculate the bearing capacity of an element under the action of torsion are the following:

1. Using the formula (25) we calculate the boundary bearing torsion moment of a concrete reinforced element when we have the class of concrete and the dimensions of the transverse section. Usually the angle is $\theta=45^{\circ}$.

2. If the torsion acting moment is greater the boundary bearing moment calculated by the formula (25) we must raise the dimensions of the transverse section or the class of concrete. 
3. If the torsion acting moment is lower than the boundary bearing moment calculated by the formula (25), by using the formula (36) we define the amount of the longitudinal reinforcement that is required in order to carry the torsion acting moment.

4. By using the formula (41) is defined the amount of the transverse reinforcement (stirrups) that is required to carry the torsion acting moment.

5. The amount of the longitudinal and transverse (stirrups) reinforcement required to carry torsion should not be confused with the reinforcements calculated for bending, shear, compression or tension. They should be added to the respective reinforcements calculated for bending, compression or tension.

\section{APPLICATION}

The influence of the height $(\mathrm{h})$ of the trans verse section in the bearing capacity from torsion according to Eurocode and to The Albanian Technical Rules

In this example we have taken different width values: $25 \mathrm{~cm}, 30 \mathrm{~cm}, 35 \mathrm{~cm}, 40 \mathrm{~cm}, 45 \mathrm{~cm}, 50 \mathrm{~cm}, 55 \mathrm{~cm}$ and we have calculated in each case the boundary bearing torsional moment that the section is able to carry according to both of the codes. The results defined by the calculations are presented in the table below:

Table 1

\begin{tabular}{|c|r|r|r|r|r|r|r|}
\hline $\mathrm{b}(\mathrm{cm})$ & 30 & 30 & 30 & 30 & 30 & 30 & 30 \\
\hline $\mathrm{h}(\mathrm{cm})$ & 25 & 30 & 35 & 40 & 45 & 50 & 55 \\
\hline $\mathrm{d}(\mathrm{cm})$ & 21.5 & 26.5 & 31.5 & 36.5 & 41.5 & 46.5 & 51.5 \\
\hline $\mathrm{Asl}(\mathrm{cm})$ & 2.26 & 2.26 & 2.26 & 2.26 & 2.26 & 2.26 & 2.26 \\
\hline $\mathrm{Asc}(\mathrm{cm} 2)$ & 4.52 & 4.52 & 4.52 & 4.52 & 4.52 & 4.52 & 4.52 \\
\hline $\mathrm{Asw}(\mathrm{cm} 2)$ & 0.5 & 0.5 & 0.5 & 0.5 & 0.5 & 0.5 & 0.5 \\
\hline $\mathrm{fck}(\mathrm{daN} / \mathrm{cm} 2)$ & 200 & 200 & 200 & 200 & 200 & 200 & 200 \\
\hline $\mathrm{fcd}(\mathrm{daN} / \mathrm{cm} 2)$ & 113.33 & 113.33 & 113.33 & 113.33 & 113.33 & 113.33 & 113.33 \\
\hline $\mathrm{Rb}(\mathrm{daN} / \mathrm{cm} 2)$ & 141.67 & 141.67 & 141.67 & 141.67 & 141.67 & 141.67 & 141.67 \\
\hline $\mathrm{fyd}(\mathrm{daN} / \mathrm{cm} 2)$ & 2150 & 2150 & 2150 & 2150 & 2150 & 2150 & 2150 \\
\hline $\mathrm{s}(\mathrm{cm})$ & 10 & 10 & 10 & 10 & 10 & 10 & 10 \\
\hline $\mathrm{M}(\mathrm{daNcm})$ & 270000 & 270000 & 270000 & 270000 & 270000 & 270000 & 270000 \\
\hline $\mathrm{Q}(\mathrm{daN})$ & 4050 & 4050 & 4050 & 4050 & 4050 & 4050 & 4050 \\
\hline $\mathrm{T}(\mathrm{daNcm})$ & 185000 & 185000 & 185000 & 185000 & 185000 & 185000 & 185000 \\
\hline $\mathrm{c}$ & 75 & 75 & 75 & 75 & 75 & 75 & 75 \\
\hline $\mathrm{tg} \theta$ & 1 & 1 & 1 & 1 & 1 & 1 & 1 \\
\hline $\mathrm{cotg} \theta$ & 1 & 1 & 1 & 1 & 1 & 1 & 1 \\
\hline $\mathrm{u}(\mathrm{cm})$ & 110 & 120 & 130 & 140 & 150 & 160 & 170 \\
\hline $\mathrm{A}(\mathrm{cm} 2)$ & 750 & 900 & 1050 & 1200 & 1350 & 1500 & 1650 \\
\hline $\mathrm{t}(\mathrm{cm})$ & 6.818 & 7.500 & 8.077 & 8.571 & 9.000 & 9.375 & 9.706 \\
\hline $\mathrm{bi}(\mathrm{cm})$ & 23.182 & 22.500 & 21.923 & 21.429 & 21.000 & 20.625 & 20.294 \\
\hline $\mathrm{hi}(\mathrm{cm})$ & 18.182 & 22.500 & 26.923 & 31.429 & 36.000 & 40.625 & 45.294 \\
\hline $\mathrm{Ak}(\mathrm{cm} 2)$ & 421.488 & 506.250 & 590.237 & 673.469 & 756.000 & 837.891 & 919.204 \\
\hline $\mathrm{uk}(\mathrm{cm})$ & 82.727 & 90.000 & 97.692 & 105.714 & 114.000 & 122.500 & 131.176 \\
\hline $\mathrm{Ta}(\mathrm{daNcm})$ & 102369.9 & 122011.9 & 140603.2 & 158301.6 & 175234.6 & 191506.6 & 207203.7 \\
\hline $\mathrm{Tb}(\mathrm{daNcm})$ & 109329.7 & 122322.5 & 134427.9 & 145888 & 156864.1 & 167467.9 & 177779.2 \\
\hline & & & & & & & 150 \\
\hline
\end{tabular}




\begin{tabular}{|c|r|r|r|r|r|r|r|}
\hline $\mathrm{Tc}(\mathrm{daNcm})$ & 141733.6 & 171472.2 & 200138.3 & 227892.8 & 254865.9 & 281164.3 & 306875.8 \\
\hline $\mathrm{T}(\mathrm{daNcm})$ & 102369.9 & 122011.9 & 134427.9 & 145888 & 156864.1 & 167467.9 & 177779.2 \\
\hline $\mathrm{TRd}(\mathrm{daNcm})$ & 140132.1 & 163507.5 & 185615 & 206706 & 226985.7 & 246616.9 & 265726.7 \\
\hline
\end{tabular}

The results are also presented in a graph:

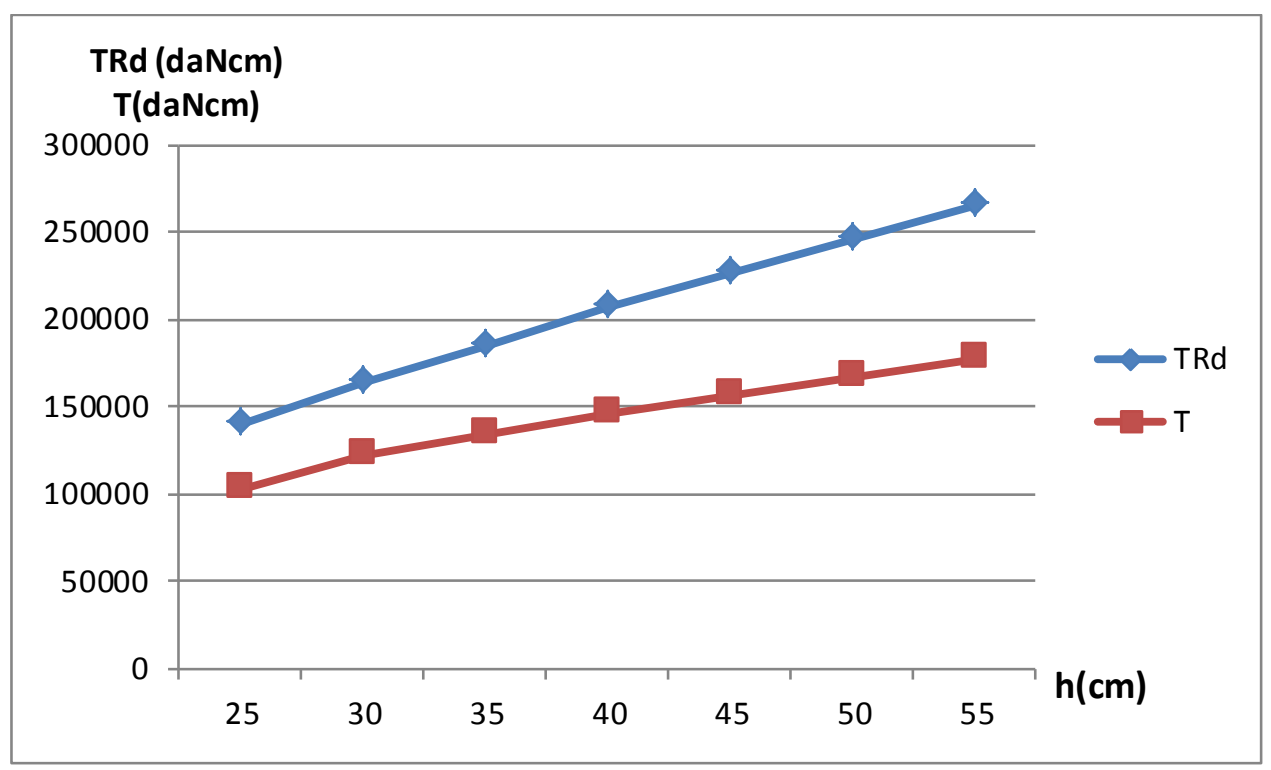

Fig.7 Relation between Trd-h and T-h

\section{CONCLUSIONS}

From the graphic in Fig.7 we notice that by increasing the height of the section, the torsion moment carried by the element calculated according to the Albanian rules, increases. The torsion moments calculated according to Eurocode also increases. The increase of the height of the section almost has the same effect in both of the calculating methods that we have studied in this article.

\section{REFERENCES}

[1] Eurocode

[2] Albania technical rules 